\title{
Insulin secretion defects in liver cirrhosis can be reversed by glucagon-like peptide-1
}

\author{
E G Siegel ${ }^{1}$, A Seidenstücker ${ }^{1}$, B Gallwitz ${ }^{1}$, F Schmitz ${ }^{1}$, \\ A Reinecke-Lüthge $^{2}$, G Klöppel ${ }^{2}$, U R Fölsch ${ }^{1}$ and W E Schmidt ${ }^{1}$ \\ ${ }^{1}$ Laboratory of Molecular Gastroenterology and Hepatology, Gastrointestinal Unit, 1st Department of Medicine, Christian-Albrechts-University of Kiel, \\ 24105 Kiel, Germany \\ ${ }^{2}$ Institute of Pathology, Christian-Albrechts-University of Kiel, 24105 Kiel, Germany \\ (Requests for offprints should be addressed to E G Siegel, Laboratory of Molecular Gastroenterology and Hepatology Gastrointestinal Unit, \\ 1 st Department of Medicine, Christian-Albrechts-University of Kiel, Schittenhelmstr. 12, D-24105 Kiel, Germany)
}

\begin{abstract}
Liver cirrhosis is often accompanied by a disturbed carbohydrate metabolism similar to type 2 diabetes. To investigate the severity of the defect in insulin secretion in this form of diabetes, we measured insulin release from isolated pancreatic islets of rats with $\mathrm{CCl}_{4}-$ phenobarbitalinduced liver cirrhosis. Cirrhosis was confirmed by clinical signs, elevated liver enzymes and histology. Fasting venous plasma glucose concentrations were equal in rats with liver cirrhosis and in controls. Plasma insulin and glucagon concentrations were significantly greater $(P<0.01)$ in cirrhotic rats than in control animals. Glucose $(16.7 \mathrm{mM})-$ induced stimulation of insulin release from pancreatic islets revealed a twofold increase in control and cirrhotic rats. Basal and stimulated insulin secretion, however, were significantly lower in cirrhotic animals. The incretin
\end{abstract}

hormone, glucagon-like peptide-1 (GLP-1), has therapeutic potential for the treatment of type 2 diabetes. Therefore, islets from control and cirrhotic animals were incubated with GLP-1 in concentrations from $10^{-11}$ to $10^{-6} \mathrm{M}$. GLP-1 stimulated insulin release in a concentration-dependent manner. In islets from cirrhotic rats, basal and stimulated insulin secretion was blunted compared with controls. These data show that the hyperinsulinemia observed in liver cirrhosis is not due to an increase of insulin secretion from islets, but could be explained by decreased hepatic clearance of insulin. GLP-1 may ameliorate diabetes in patients with liver cirrhosis.

Journal of Endocrinology (2000) 164, 13-19

\section{Introduction}

The association of liver disease with abnormalities of carbohydrate metabolism was recognized by Naunyn (1898) 100 years ago, and the metabolic disturbances of glucose and insulin homeostasis have been intensively investigated in both humans and animal models (Conn et al. 1971, Felig \& Sherwin 1976, Petrides \& DeFronzo $1989 a, b)$. Most patients with liver cirrhosis are intolerant to oral glucose, even when their fasting blood glucose concentration is normal. Impaired regulation of carbohydrate metabolism includes glucose intolerance, hyperinsulinemia and hyperglucagonemia (Holdsworth et al. 1972, Silva et al. 1988). On the basis of World Health Organization Criteria, more than $70 \%$ of patients with cirrhosis have oral glucose intolerance, and diabetes is more prevalent in these patients than in the general population (Kruszynska \& McIntyre 1991). The impaired glucose tolerance is due mainly to insulin resistance of peripheral tissues (Kruszynska et al. 1991, 1993). Both insulin resistance and consecutive relative impairment of insulin secretion (Taylor et al. 1985) have been considered important. The exact cause of these abnormalities remains unclear. Petrides \& DeFronzo (1989a) suggested that hyperinsulinemia is caused by increased insulin secretion and diminished insulin degradation by the liver in cirrhosis. However, the picture is complicated by divergent data. Sirinek et al. (1991) demonstrated that extrahepatic porto-systemic shunting plays little or no role in the hyperinsulinemia of cirrhosis. Nakamura et al. (1988) showed that insulin release from the isolated perfused pancreas of rats with cirrhosis was decreased. Moreover, these results are in contrast to clinical investigations using the minimal model technique or euglycemic and hyperglycemic clamps (Kruszynska et al. 1991). Insulin secretion was greater in patients with cirrhosis, both in the fasting state and during the hyperglycemic clamp. After an oral glucose load, however, the increase in serum C-peptide concentration was relatively delayed and the insulin secretion index was not increased. Hepatic insulin extraction was reduced in the fasting state and during the hyperglycemic clamp. Thus, hypersecretion and decreased 
insulin clearance were postulated to result in increased insulin concentrations in patients with cirrhosis.

Numerous studies have shown that glucagon-like peptide-1 (GLP-1) a 30-residue gastrointestinal hormone released from the enteroglucagon cells (L-cells) in the small intestine (Orskov et al. 1987) stimulates insulin secretion in vitro and in vivo (Schmidt et al. 1985, Kreymann et al. 1987, Orskov 1992, Ritzel et al. 1995), and potently influences postprandial glycemic concentrations. Moreover, it is also effective in patients with diabetes (Gutniak et al. 1992, Nathan et al. 1992), normalizing blood glucose concentrations in patients with type 2 diabetes (Nauck et al. 1993) and improving glycemic control in type 1 patients (Creutzfeldt et al. 1996), raising the possibility of its use as a therapeutic agent.

GLP-1 has, however, a plasma half-life of only 1-2 min in vivo (Mentlein et al. 1993, Pridal et al. 1996). The short insulinotropic action results from the degradation of the peptide by dipeptidyl peptidase IV that degrades GLP-1 at the $\mathrm{N}$-terminus by cleaving off the first two amino acids, generating biologically inactive fragments (Deacon et al. 1995). Another enzymatic cleavage site of GLP-1 is located between amino acids 8 and 9. This metabolic instability, together with the formation of a metabolite [GLP-1(9-36)amide] that can antagonize the effects of GLP-1 (Knudsen \& Pridal 1996) may limit the therapeutic potential of native GLP-1. In previous experiments, we demonstrated that GLP-1 analogs with alterations in the positions 2 or 2 and 8 significantly increased insulin release in the presence of $16.7 \mathrm{mM}$ glucose, and were resistant to degradation by dipeptidyl peptidase IV (Siegel et al. 1999).

In the present study, we characterized the dynamics of insulin secretion in response to $\mathrm{D}$-glucose to determine whether pancreatic endocrine function is altered in rats with cirrhosis, augmenting the type 2 diabetes-like metabolic situation that is associated with liver cirrhosis.

\section{Materials and Methods}

\section{Peptide synthesis}

GLP-1 was synthesized by solid-phase methodology on the polyamine resin Ultrosyn A (Pharamacia LKB, Freiburg, Germany) using $\mathrm{N}$-fmoc-protected amino acid pentafluorophenylesters in an automatic peptide synthesizer (Novasyn Crystal; Calbiochem, Heidelberg, Germany) (Dryland \& Sheppard 1986). GLP-1 was cleaved from the resin by treatment with $5 \%(\mathrm{v} / \mathrm{v})$ thioanisol in trifluoracetic acid for $2 \mathrm{~h}$. The peptide was purified by gel filtration on Sephadex G 10 and preparative HPLC on a C18 Nueleosil 300-7 wide-pore MN column (30 nm, $1 \times 25 \mathrm{~cm}$ ) (Machery and Nagel, Düren, Germany). The quality of the synthetic peptides was assessed by mass spectrometry and automatic amino acid analysis (Schmidt et al. 1988).

\section{Oral glucose tolerance tests}

Animals were fasted for $12 \mathrm{~h}$ before oral glucose tolerance tests. After pentobarbital anesthesia, one polyethylene catheter was inserted into the left carotid vein for blood sampling. D-Glucose ( $3 \mathrm{~g} / \mathrm{kg}$ body weight) was administered through an orogastric tube into the distal esophagus. Blood samples $(125 \mu \mathrm{l})$ were taken $10 \mathrm{~min}$ before and 10 , 30, 60, 120 and $180 \mathrm{~min}$ after glucose administration, for the measurement of plasma glucose concentrations (Glucose Analyzer II, Beckman) and serum insulin concentrations (radioimmunoassay).

\section{Induction of cirrhosis}

Cirrhosis was induced with $\mathrm{CCl}_{4}$ and phenobarbital as described by Jimenez et al.(1985). For $\mathrm{CCl}_{4}$ application, animals were placed in a plastic box $(80 \times 40 \times 40 \mathrm{~cm})$. Flowmeter-controlled compressed air was passed through a flask containing $\mathrm{CCl}_{4}$ and introduced into the box. Animals inhaled $\mathrm{CCl}_{4}$ twice a week for $0.5 \mathrm{~min}$ at a flow of $2.5 \mathrm{l} / \mathrm{min}$ initially, followed by stepwise increases in exposure time up to $8 \mathrm{~min}$ at the 10th week of treatment. Drinking water was supplemented with phenobarbital in a concentration of $0.03 \%$. Control animals were kept under identical conditions except for the exposure to either agent. Cirrhosis was verified at the end of individual experiments by gross inspection of the liver, by the presence of ascites, and by histopathologic examination of the liver using standard techniques for fixation and staining (Batts \& Ludwig 1995). Rats not showing cirrhosis by microscopic examination ( $<5 \%$ of treated animals) were excluded from further analysis. By the time of the experimental studies, both cirrhotic and control rats had a body weights of $280-300 \mathrm{~g}$.

\section{Stimulation of isolated rat islets with GLP-1 and determination of insulin release}

Pancreatic islets were isolated by collagenase digestion (Siegel \& Creutzfeldt 1985) from male Lewis rats weighing 250-300 g after an overnight fast; collagenase was from Biochrom, Berlin, Germany. Batches of 200-400 islets with a diameter of greater than 150 ( $\mu \mathrm{m}$ were maintained in tissue culture medium (RPMI-1640, Biochrom) for 20-24 h at an ambient glucose concentration of $11 \mathrm{mM}$. The medium was supplemented with $10 \%$ fetal calf serum (Biochrom), $100 \mathrm{U} / \mathrm{ml}$ penicillin $\mathrm{G}$ and streptomycin 100 $\mu \mathrm{g} / \mathrm{ml}$. The islets were maintained at $37^{\circ} \mathrm{C}, \mathrm{pH} 7 \cdot 4$ in an atmosphere saturated with water and gassed with an air- $5 \% \mathrm{CO}_{2}$ mixture.

After the maintenance period, the islets were washed and incubated in a modified Krebs-Ringer bicarbonate buffer (KRB-HEPES) as described previously (Siegel \& Creutzfeldt 1985). Ten islets per vial were incubated for $30 \mathrm{~min}$ in $2 \mathrm{ml} \mathrm{KRB-HEPES}$ at $37^{\circ} \mathrm{C}$, pH $7 \cdot 4$ containing 
Table 1 Liver function tests in normal and cirrhotic rats. Values are mean \pm S.E.M. for $n=15$ rats per group

\begin{tabular}{|c|c|c|c|c|c|c|}
\hline & $\begin{array}{l}\text { ASAT } \\
(\mathrm{U} / \mathrm{l})\end{array}$ & $\begin{array}{l}\text { ALAT } \\
(U / \mathrm{I})\end{array}$ & $\begin{array}{l}\text { AP } \\
(U / I)\end{array}$ & $\begin{array}{l}\text { Bilirubin } \\
(\mathrm{mg} / \mathrm{dl})\end{array}$ & $\begin{array}{l}\text { Total protein } \\
(\mathrm{g} / \mathrm{l})\end{array}$ & $\begin{array}{l}\text { GGT } \\
(\mathrm{U} / \mathrm{I})\end{array}$ \\
\hline \multicolumn{7}{|l|}{ Group } \\
\hline Control & $42 \cdot 57 \pm 5 \cdot 35$ & $21 \cdot 27 \pm 1 \cdot 7$ & $145 \cdot 7 \pm 50 \cdot 1$ & $0 \cdot 08 \pm 0 \cdot 01$ & $5.57 \pm 0.06$ & $1 \cdot 14 \pm 0 \cdot 14$ \\
\hline Cirrhosis & $266 \cdot 1 \pm 46 \cdot 7$ & $164 \cdot 7 \pm 32 \cdot 9$ & $316 \cdot 6 \pm 45 \cdot 8$ & $0 \cdot 57 \pm 0 \cdot 16$ & $5 \cdot 00 \pm 0 \cdot 25$ & $4 \cdot 30 \pm 0.96$ \\
\hline$P \dagger$ & $0 \cdot 003$ & $0 \cdot 005$ & 0.030 & $0 \cdot 041$ & $0 \cdot 11$ & $0 \cdot 029$ \\
\hline
\end{tabular}

†For comparison between control and cirrhosis groups.

the respective stimulating agent. Insulin release was measured by radioimmunoassay (Siegel \& Creutzfeldt 1985).

\section{Liver function tests}

To assess liver function in control and cirrhotic rats after 10 weeks of treatment, serum was collected from $n=15$ rats per group to determine activities of aspartate aminotransferase (ASAT), alanine aminotransferase (ALAT), alkaline phosphatase (AP), and gamma glutamyl transferase (GGT) using the Automatic Analyzer 717 from BoehringerMannheim, Mannheim, Germany. Further serum analyses included total protein and total bilirubin concentration (Table 1).

\section{Determination of serum glucagon concentration}

For the quantitative determination of pancreas-specific glucagon in rat serum, a glucagon radioimmunoassay kit from DRG Diagnostics (Marburg, Germany) was utilized. The glucagon antibody showed no crossreactivity greater than $0 \cdot 1 \%$ with oxyntomodulin. Assay sensitivity was $20 \mathrm{pg} / \mathrm{ml}$. The interassay coefficient of variation was less than $10 \%$, and the intra-assay variation was below $6 \%$.

\section{Statistical analysis and calculations}

Variance of individual group means was calculated with a one-way ANOVA test, and a Fisher's post-hoc test was used for group comparisons.

\section{Results}

The rats in the $\mathrm{CCl}_{4}$-treated group showed an unhealthy appearance and transparent ascites was seen in most rats with cirrhosis when the abdomen was opened. The increase in body weight was not significantly different between the groups. The size and weight of the livers in the $\mathrm{CCl}_{4}$-treated rats were increased and the surface demonstrated typical appearances of micronodular cirrhosis. The mean liver weight ( \pm s.E.M) was $7.5 \pm 0.7 \mathrm{~g}$ in the control group and $12.3 \pm 0.9 \mathrm{~g}$ in the cirrhosis group. The ratio of liver weight to body weight was $2 \cdot 54 \pm 0 \cdot 13 \%$ in the control group and $4 \cdot 24 \pm 0 \cdot 08 \%$ in the cirrhosis group. The liver weight and the ratios of liver weight to body weight were significantly greater in cirrhotic animals $(P<0 \cdot 01)$.

The results of the liver function tests are shown in Table 1. Blood glucose concentrations were not different in the two groups of animals studied (controls: $84 \pm 6.3 \mathrm{mg} / \mathrm{dl}$; cirrhotic rats: $86.7 \pm 5.8 \mathrm{mg} / \mathrm{dl}$, not significant). Cirrhotic rats had significantly greater insulin and glucagon plasma concentrations than control rats, thus demonstrating hyperinsulinemia and hyperglucagonemia (Table 2).

\section{Oral glucose tolerance tests}

As depicted in Fig. 1, basal plasma glucose concentrations were not different in control and cirrhotic rats $(5 \cdot 61 \pm 0.23 \mathrm{mM}$ compared with $5 \cdot 23 \pm 0.19 \mathrm{mM})$. Basal insulin concentrations, however, were significantly greater in cirrhotic rats than in controls $(1.63 \pm 0.1 \mathrm{ng} / \mathrm{ml}$ compared with $0.63 \pm 0.06 \mathrm{ng} / \mathrm{ml})$. After an oral glucose load, blood glucose concentrations in untreated and cirrhotic animals were within normal limits throughout the experiment.

Insulin concentrations declined over time, but remained increased in the $\mathrm{CCl}_{4}$-treated group, even after decrease of blood glucose concentration to normal fasting values after $180 \mathrm{~min}$. In cirrhotic rats, insulin concentrations increased 1.7-fold upon stimulation with orally administered glucose, whereas healthy rats had a $3 \cdot 3$-fold increase in insulin concentration.

Table 2 Plasma insulin and glucagon concentrations in control rats and rats with liver cirrhosis. Results are expressed as mean \pm S.D. $(n=15$ rats per group)

\begin{tabular}{|c|c|c|}
\hline & Controls & Cirrhotic \\
\hline Insulin $(\mu \mathrm{U} / \mathrm{ml})$ & $10 \cdot 3 \pm 2 \cdot 8$ & $39 \cdot 9 \pm 5 \cdot 6^{* *}$ \\
\hline Glucagon (pg/ml) & $54 \cdot 5 \pm 5 \cdot 3$ & $157 \cdot 6 \pm 22 \cdot 4^{* *}$ \\
\hline
\end{tabular}

Journal of Endocrinology (2000) 164, 13-19 

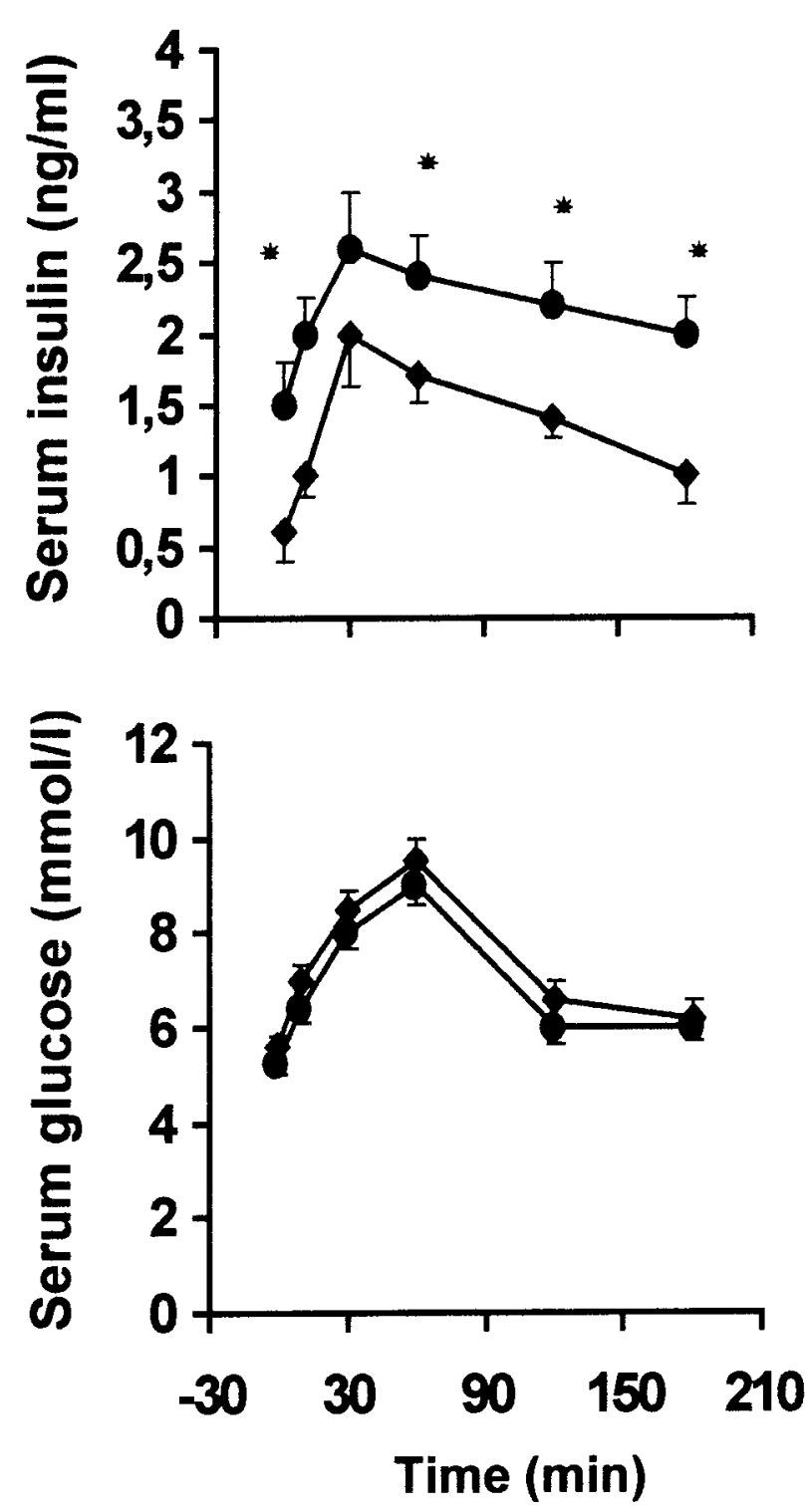

Figure 1 Oral glucose tolerance test. Plasma concentrations of glucose (lower panel) and insulin (upper panel) in control $(\bullet)$ and cirrhotic $(\bigcirc)$ rats. Values represent means \pm S.E.M., $n=15$ rats per group. Oral glucose was given at $\mathrm{t}=0 \mathrm{~min}$. ${ }^{*}$ Significant difference $(P<0.01)$ compared with the control group at corresponding time points.

\section{Stimulation of insulin secretion}

Glucose $(16.7 \mathrm{mM})$ induced a twofold increase in insulin release from isolated pancreatic islets of both normal rats (basal $3 \cdot 0 \pm 0 \cdot 2 \mathrm{ng} / 10$ islets per $30 \mathrm{~min}$; stimulated $6 \cdot 0 \pm 0.5 \mathrm{ng} / 10$ islets per $30 \mathrm{~min} ; P<0 \cdot 05)$ and cirrhotic rats (basal $1 \cdot 1 \pm 0 \cdot 1 \mathrm{ng} / 10$ islets per $30 \mathrm{~min}$; stimulated $1 \cdot 9 \pm 0 \cdot 2 \mathrm{ng} / 10$ islets per $30 \mathrm{~min} ; P<0 \cdot 05$ ) (Fig. 2). GLP-1 exerted insulinotropic effects in islets from normal and cirrhotic rats in a dose-dependent manner. Addition

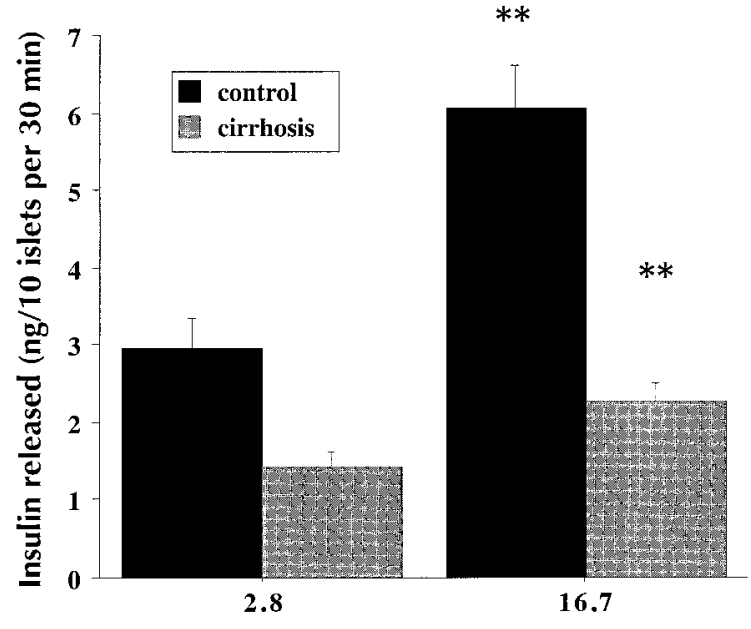

Glucose (mM)

Figure 2 Stimulation of insulin release by glucose. Pancreatic islets from control and cirrhotic rats were isolated by collagenase digestion as described in Material and Methods. Islets were incubated after 24-h maintenance in tissue culture in KRB-HEPES buffer for $30 \mathrm{~min}$. Insulin release was measured in the presence of $2 \cdot 8$ and $16.7 \mathrm{mM}$ glucose. Values are means \pm S.E.M., $n=15$ rats per group, ${ }^{* *} P<0 \cdot 01$.

of $10^{-9} \mathrm{M}$ GLP-1 resulted in a significant $(P<0 \cdot 05)$ enhancement of insulin release, to $3 \cdot 10 \pm 0 \cdot 17 \mathrm{ng}$ per 10 islets from cirrhotic rats. A concentration of $10^{-7} \mathrm{M}$ of GLP-1 caused a further increase (4.05 $\pm 0 \cdot 44 \mathrm{ng} / 10$ islets) that was almost $200 \%$ compared with glucose alone. When additional concentrations of GLP-1 were tested in separate series, no effect was seen with $10^{-10} \mathrm{M}$ and no further increase at $10^{-6} \mathrm{M}$ compared with the effect achieved with $10-{ }^{7} \mathrm{M}$ (Fig. 3).

\section{Discussion}

In this study, an experimental model of liver cirrhosis in rats was used to characterize insulin secretion in this condition, which often is accompanied by a form of diabetes similar to type 2 diabetes. Of the several ways to induce cirrhosis by $\mathrm{CCl}_{4}$ alone or combined with other substances (Tamayo 1983, Qazi \& Alam Mahmood 1988), we utilized a combined method with $\mathrm{CCL}_{4}$ and pentobarbital. The mortality of rats in the present study was $<5 \%$. Most rats in the cirrhosis group showed ascites. The macroscopic appearance, the increased liver weight and the ratio of liver weight to body weight, the histologic features and the abnormal liver function test all indicate that hepatocyte degeneration and necrosis persisted throughout the entire course of induction of cirrhosis. This model showed fasting hyperinsulinemia and a degree of insulin resistance during euglycemic hyperinsulinemic 


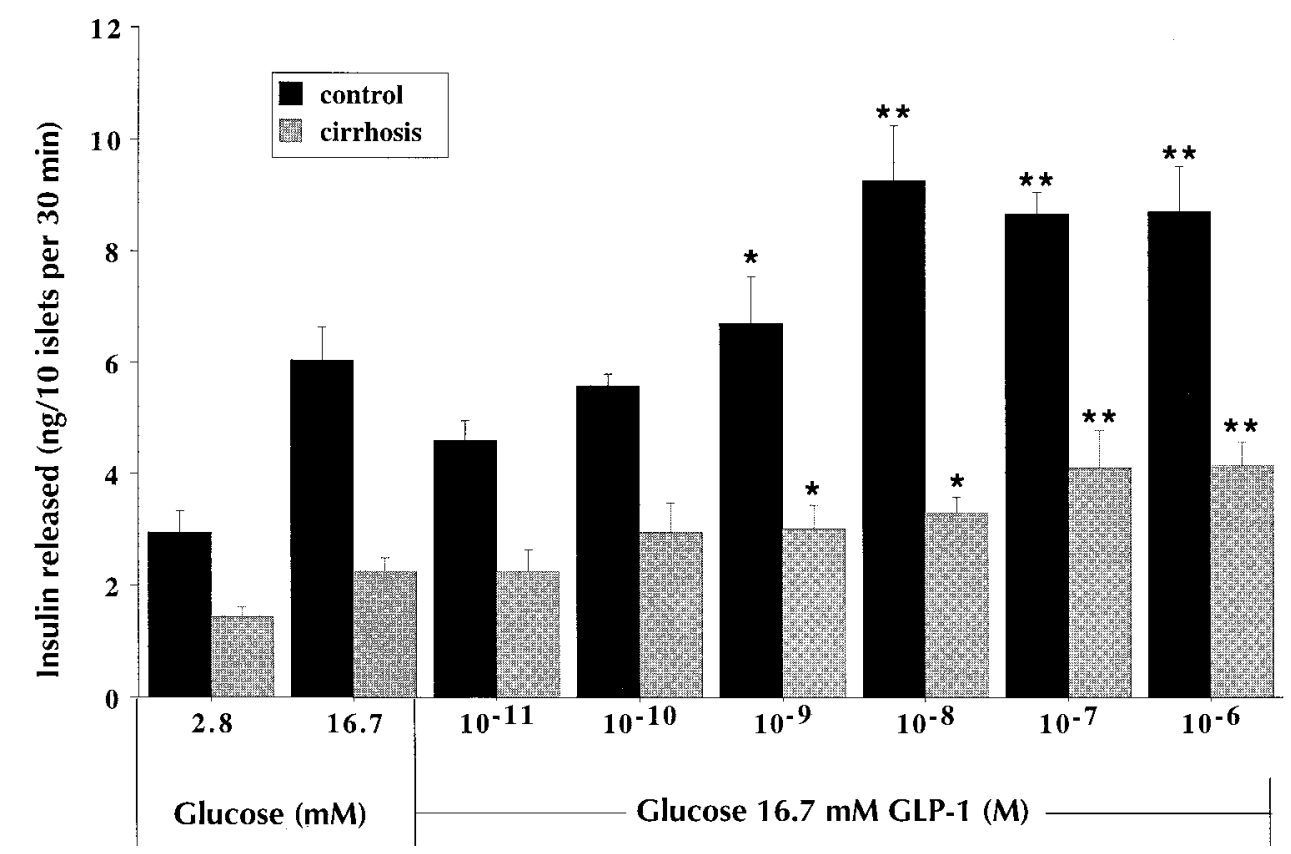

Figure 3 Effect of GLP-1 on insulin release by pancreatic islets from control and cirrhotic rats. Rat islets were isolated by collagenase digestion and preincubated for $24 \mathrm{~h}$. Static incubations of 10 islets per vial were performed for $30 \mathrm{~min}$ in the presence of $16.7 \mathrm{mM}$ glucose and with the indicated concentrations of GLP-1. Insulin release was measured by radioimmunoassay. Values are means \pm S.E.M. for 15 separate experiments. ${ }^{*} P<0 \cdot 05,{ }^{*} P<0 \cdot 01$, compared with corresponding controls at $16.7 \mathrm{mM}$ glucose in the absence of GLP-1.

clamp studies comparable to those reported in humans (Meyer-Alber et al. 1992). Furthermore, compared with values in healthy rats, after i.v. infusion of insulin, increased serum insulin concentrations were observed. This phenomenon has also been described in patients with cirrhosis, and has been explained at least partially by decreased hepatic function and porto-systemic shunting (Petrides \& DeFronzo 1989b). The pancreatic tissue of the $\mathrm{CCl}_{4}$-treated rats showed normal histology of the exocrine and endocrine portions of the pancreas consistent with the observations of Nakamura et al. (1988) and $\mathrm{Wu}$ et al. (1994). Therefore, the abnormal glucose metabolism and insulin secretion do not seem to have been a consequence of direct toxic action by $\mathrm{CCl}_{4}$ on the pancreatic islets.

Hyperinsulinemia in cirrhosis may be caused by several factors. In our study, peripheral hyperinsulinemia did not seem to be caused by increased insulin secretion, as insulin release by isolated islets from the $\mathrm{CCl}_{4}$-treated rats showed both reduced glucose-induced insulin secretion and reduced basal release. In clinical studies, increased insulin secretion in patients with liver cirrhosis has been considered to be a compensatory mechanism for the development of peripheral insulin resistance in order to maintain normal blood glucose concentrations (Petrides \& DeFronzo 1989a). In the present study, the finding of normal fasting glucose concentrations does not support the idea of compensatory secretion. 1t seems more reasonable that the hyperinsulinemia can be attributed to reduced liver insulin extraction, due to impaired hepatocyte function. A large number of investigators (Nygren et al. 1985, Petrides \& DeFronzo 1989a, b, Kruszynska et al. 1991) have, directly or indirectly, shown that reduced insulin clearance by the liver cirrhosis, contributes to hyperinsulinemia, and this may be the main explanation for the hyperinsulinemia encountered in this study.

Little is known about the in vitro function of pancreatic islets in cirrhosis. Gomis et al. (1994) demonstrated, in vitro in isolated pancreatic islets, that the defect in the $\beta$-cell response to glucose stimulation contrasts with the unimpaired response to arginine. This may reflect a specific defect in glucose metabolism in the pancreatic $\beta$ cells. The insulinotropic action of arginine is attributed to the depolarization of the $\beta$-cell membrane (Malaisse et al. 1989); thus a normal response to arginine stimulation suggests that the cytoplasmatic membrane and ionic channels are preserved in $\beta$ cells from cirrhotic rats. Kruszynska et al. (1998) demonstrated that insulin hypersecretion in non-diabetic alcoholic patients might result from enhanced islet $\beta$-cell sensitivity to glucose or an increased maximal secretory capacity. Conversely, impaired insulin secretion in diabetic alcoholic patients 
with cirrhosis could be due to decreased $\beta$-cell sensitivity or diminished secretory capacity. Previous findings by Kruszynska et al. (1993) of a prompt output of insulin in response to i.v. tolbutamide in diabetic patients with cirrhosis who lacked a first-phase insulin response to glucose suggest that the insulin secretory defect may be relatively specific for glucose.

The finding that the acute insulin secretory response to arginine in diabetic patients with cirrhosis was not significantly different from that of controls or non-diabetic patients with cirrhosis supports this idea. Specific alterations in glucose metabolism may impair insulin secretion by interfering at the intracellular level, suggesting that the abnormal insulin response to glucose stimulation exhibited by pancreatic islets from rats with cirrhosis and diabetic patients with cirrhosis could reflect a defect at the mitochondrial level. In addition, there is a possibility that hyperammonemia could impair the pancreatic response to a glucose stimulus by decreasing NADPH (Sener et al. 1978) and increasing intracellular $\mathrm{pH}$ (Smith \& Pace 1983). This possibility should be considered, because hyperammonemia is a component of the portal hypertension syndrome.

Our study shows that isolated islets from rats with $\mathrm{CCl}_{4}$-induced liver cirrhosis exhibit an impaired insulin secretion in response to stimulation with glucose in vitro. The endocrine dysfunction in cirrhosis is further supported by our observation in vivo after an oral glucose tolerance test. Cirrhotic and healthy rats had identical serum glucose concentrations after an oral glucose load, whereas insulin concentrations were significantly different at all timepoints of the experiment. In cirrhotic rats, serum insulin concentrations were greater at baseline and increased 1.7-fold at maximum, $40 \mathrm{~min}$ after glucose instillation. In the control animals, serum insulin concentrations increased $3 \cdot 3$-fold at maximum

We conclude that GLP-1 exerts insulinotropic effects on islets from normal and cirrhotic rats in a dosedependent manner. Our study also shows that isolated pancreatic islets from rats with cirrhosis exhibit an abnormal endocrine pancreatic secretion, characterized by impaired insulin secretion in response to glucose stimulation. Studies of insulin secretion in the islets from $\mathrm{CCl}_{4}$-treated rats revealed that basal and glucosestimulated insulin release was reduced. Cirrhotic rats had a normal glucose tolerance test in the presence of marked hyperinsulinemia. This raises the question whether hypersecretion of insulin or reduced degradation by impaired liver function account for the increased basal and postprandial insulin concentrations in cirrhosis. As the magnitude of the response of insulin secretion was decreased both in vitro and in vivo, our findings are in favor of a reduced insulin degradation.

The gastrointestinal hormone, GLP-1, is the most important incretin stimulating insulin secretion after a carbohydrate-rich meal (Schmidt et al. 1985, Kreyman et al. 1987). As it also stimulates insulin secretion and inhibits glucagon secretion in patients with type 2 diabetes, the use of GLP-1 might be also a potential therapeutic option for the treatment of diabetes associated with liver cirrhosis.

\section{Acknowledgements}

The authors express their gratitude to M Witt and E Jürgen for excellent technical assistence. This study was supported by a grant from the Christian-AlbrechtsUniversity (Hensel foundation).

\section{References}

Batts KP \& Ludwig J 1995 Chronic hepatitis. An update on terminology and reporting. American Journal of Surgical Pathology 19 1409-1417.

Conn HO, Schreider W \& Elkington SG 1971 Cirrhosis and diabetes II. Association of impaired glucose tolerance with portal-systemic shunting in Laennec's cirrhosis. American Journal of Digestive Diseases $16227-239$

Creutzfeldt W, Kleine N, Willms B Orskov C, Holst JJ \& Nauck MA 1996 Glucagonostatic actions and reduction of fasting hyperglycemia by exogenous glucagon-like peptide-1 (7-36amide) in type 1 diabetic patients. Diabetes Care 19 580-586.

Deacon CF, Nauck MA, Toft-Nielsen M Pridal L, Willms B \& Holst JJ 1995 Both subcutaneously and intravenously administered glucagon-like pepitde-1 are rapidly degraded from the NH2terminus in type 2 diabetic patients and in healthy subjects. Diabetes 44 1126-1131.

Dryland A \& Sheppard RC 1986 Peptide synthesis VIII. A system for solid phase synthesis under low pressure continuous flow conditions. Perkin Transactions 1 125-137.

Felig P \& Sherwin R 1976 Carbohydrate homeostasis liver and diabetes. In Progress in Liver Disease, vol 5, pp 149-171. New York: Grune and Stratton.

Gomis R, Fernandez-Alvarez J, Pizcueta P Fernandez M, Casamitjana R, Bosch J \& Rodes J 1994 Impaired function of pancreatic islets from rats with portal hypertension from cirrhosis and portal vein ligation. Hepatology 19 1257-1261.

Gutniak M, Orskov C, Holst JJ, Ahren B \& Efendic S 1992 Antidiabetogenic effect of glucagon-like peptide-1 (7-36)amide in normal subjects and patients with diabetes mellitus. New England Journal of Medicine 326 1316-1322.

Holdsworth CD, Nye L \& King E 1972 The effect of porto-caval anastomosis on oral carbohydrate tolerance and on plasma insulin levels. Gut 13 58-63.

Jiminez W, Martinez-Pardo A, Arroyo V, Bruix J, Rimola A, Gaya J \& Rivera F, Rodes J 1985 Temporal relationship between hyperaldosteronism, sodium retention and ascites formation in rats with experimental cirrhosis. Hepatology 5 245-250.

Knudsen LB \& Pridal L 1996 Glucagon-like peptide-1 (9-36)amide is a major metabolite of glucagon-like peptide-1 (7-36)amide after in vivo administration to dogs, and it acts as an antagonist on the pancreatic receptor. European Journal of Pharmacology 318 429-435.

Kreymann B, Williams G, Ghattei MA \& Bloom SR 1987 Glucagon-like peptide-1 (7-36): a physiological incretin in man. Lancet 2 1300-1304.

Kruszynska YT \& McIntyre N 1991 Carbohydrate metabolism. In Oxford Textbook of Cclinical Hepatology, pp 129-143. Eds N McIntyre, PJ Benhamou, J Bircher, M Rizzetto \& J Rodes. Oxford: Oxford University Press. 
Kruszynska YT, Home PD \& McIntyre N 1991 The relationship between insulin insensitivity, insulin secretion and glucose tolerance in cirrhosis. Hepatology 14 103-111.

Kruszynska YT, Harry DS, Bergman RN \& McIntyre N 1993 Insulin insensitivity, insulin secretion and glucose effectiveness in diabetic and non-diabetic cirrhotic patients. Diabetologia 36 121-128.

Kruszynska YT, Goulas S, Wollen N \& McIntyre N 1998 Insulin secretory capacity and the regulation of glucagon secretion in diabetic and non-diabetic alcoholic cirrhotic patients. Journal of Hepatology 28 280-291.

Malaisse WJ, Blachier F, Mourtada A B Camara J, Albor A, Valverde I \& Sener A 1989 Stimulus-secretion coupling of arginine-induced insulin release. Metabolism of L-arginine and L-ornithine in pancreatic islets. Biochimica et Biophysica Acta 1013 133-143.

Mentlein R, Gallwitz B \& Schmidt WE 1993 Dipeptidyl peptidase IV hydrolyses gastric inhibitory polypeptide, glucagon-like pepetide-1 (7-36)amide, peptide histidine methionine and is responsible for their degradation in human serum. European Journal of Biochemistry $214829-835$.

Meyer-Alber A, Hartmann H, Stümpel F \& Creutzfeldt W 1992 Mechanism of insulin resistance in $\mathrm{CCl}_{4}$-induced cirrhosis of rats. Gastroenterology 102 223-229.

Nakamura T, Otsuki M \& Tani S 1988 Pancreatic endocrine function in cirrhotic rats. Metabolism 37 892-899.

Nathan DM, Schreiber E, Fogel Mojsov S \& Habener JF 1992 Insulinotropic action of glucagon-like peptide-I-(7-37) in diabetic and nondiabetic subjects. Diabetes Care 15 270-276.

Nauck MA, Kleine N, Orskov C Holst JJ, Willms B \& Creutzfeldt W 1993 Normalization of fasting hyperglycemia by exogenous glucagon-like peptide-1 (7-36amide) in type 2 (non-insulindependent) diabetic patients. Diabetologia 3 741-744.

Naunyn B 1898 Glykosurie und Diabetes durch experimentelle Insulte und Krankheiten der Leber. In Der Diabetes Mellitus, vol 7 , pp 38-49. Ed B Naunyn. Vienna, Austria: A Holder.

Nygren A, Adnev N \& Sundblad L 1985 Insulin uptake by the human alcoholic cirrhotic liver. Metabolism 34 48-52.

Orskov C 1992 Glucagon-like peptide-1, a new hormone of the enteroinsulinar axis. Diabetologia 35 701-711.

Orskov C, Holst JJ, Seier Poulsen S \& Kirkegaard P 1987 Pancreatic and intestinal processing of proglucagon in man. Diabetologia 30 874-881.

Petrides AS \& DeFronzo RA 1989a Glucose metabolism in cirrhosis: a review with some perspectives for the future. Diabetes Metabolism Reviews 5 691-709.

Petrides AS \& DeFronzo RA 19896 Glucose and insulin metabolism in cirrhosis. Journal of Hepatology 8 107-114.

Pridal L, Deacon CF, Kirk O, Christensen JV, Carr RD \& Holst JJ 1996 Glucagon-like peptide- 1(7-37) has a larger volume of distribution than glucagon-like peptide-1(7-36) amide in dogs and is degraded more quickly in vitro by dog plasma. European Journal of Drug Metabolism and Pharmacokinetics 21 51-59.
Qazi FM \& Alam Mahmood S 1988 Potentiating effects of phenobarbitone on the induction of cirrhosis in rats by carbon tetrachloride. Journal of the American Medical Association 38 296-299.

Ritzel R, Orskov C, Holst JJ \& Nauck MA 1995 Pharmacokinetic, insulinotropic, and glucagonostatic properties of GLP-1 [7-36 amide] after subcutaneous injection in healthy volunteers. Doseresponse-relationships. Diabetologia 38 720-725.

Schmidt WE, Siegel EG \& Creutzfeldt W 1985 Glucagon-like peptide- 1 but not glucagon-like peptide- 2 stimulates insulin release from isolated rat pancreatic islets. Diabetologia 28 704-707.

Schmidt WE, Siegel EG, Kratzin H \& Creutzfeldt W 1988 Isolation and primary structure of tumor-derived peptides related to human pancreastatin and chromogranin A. Proceedings of the National Academy of Sciences of the USA 85 8231-8235.

Sener A, Hutton JC, Kawazu S Boschero AC, Somers G, Devis G, Herchuelz A \& Malaisse WJ 1978 The stimulus-secretion coupling of glucose-induced insulin release. Metabolic and functional effects of $\mathrm{NH}_{4}^{+}$in rat islets. Journal of Clinical Investigation $\mathbf{6 2}$ 868-879.

Siegel EG \& Creutzfeldt W 1985 Stimulation of insulin release in isolated rat islets by GIP in physiological concentrations and its relation to islet cyclic AMP content. Diabetologia 28 857-861.

Siegel EG, Gallwitz B, Scharf G, Mentlein R, Morys-Wortmann C, Folsch UR, Schrezenmeir J, Drescher K \& Schmidt WE 1999 Biological activity of GLP-1-analogues with N-terminal modifications. Regulatory Peptides 79 93-102

Silva G, Gomis R, Bosch J Casamitjana R, Mastai R, Navasa M, Rivera F \& Rodes J 1988 Hyperglucagonism and glucagon resistence in cirrhosis. Paradoxical effect of propanolol on plasma glucagon levels. Journal of Hepatology 6 325-331.

Sirinek KR, O'Dorioso TM \& Levine BA 1991 Glucose intolerance and hyperinsulinemia of cirrhosis are not results of spontaneous or surgical portosystemic shunting. American Journal of Surgery 161 149-153.

Smith JS \& Pace CS 1983 Modification of glucose-induced insulin release by alteration of $\mathrm{pH}$. Diabetes 32 61-66.

Tamayo RP 1983 Is cirrhosis of the liver experimentally produced by $\mathrm{CCl}_{4}$ an adequate model of human cirrhosis? Hepatology 3 $112-120$

Taylor R, Heine RJ, Collins J James OF \& Alberti KG 1985 Insulin action in cirrhosis. Hepatology 5 64-71.

Wu J, Lindström P, Danjelsson A \& Sehlin J 1994 Insulin secretion in pancreatic islets from rats with cirrhosis. Journal of Hepatology 21 332-339.

Received 19 January 1999

Revised manuscript received 4 August 1999

Accepted 18 August 1999 